\title{
ANALFABETISMO AMBIENTAL: A PERCEPÇÃO DOS DOCENTES E DISCENTES SOBRE O AMBIENTE DE UMA ESCOLA DO MUNICÍPIO DE GUARAÍ-TO
}

\author{
Natanael Gomes Lima ${ }^{1}$, Karla Caroline Sousa Dornelas ${ }^{2}$, Liberta Lamarta Favoritto \\ Garcia Neres ${ }^{3}$, Ana Paula Martins Guimarães ${ }^{4}$, Júlio Cesar Ibiapina Neres ${ }^{5}$, \\ Aluísio Vasconcelos Carvalho ${ }^{6}$
}

\section{RESUMO}

O termo analfabetismo ambiental surgiu na conferência RIO-92 após destacarem a necessidade da implementação de um modelo sustentável que determinasse a relação das pessoas com os problemas ambientais, a fim de formar cidadãos comprometidos com as questões socioambientais. Neste contexto, a pesquisa teve como objetivo analisar o analfabetismo ambiental acerca da percepção dos docentes e discentes do Ensino Médio no município de Guaraí-TO, buscando identificar esse possível analfabetismo. Para o desenvolvimento deste trabalho foram utilizados recursos que auxiliassem nos levantamentos de dados, possibilitando uma visão mais clara desse possível analfabetismo por parte de professores e alunos. Através do uso de questionário e observações com o intuito de descrever as características dos entrevistados, foi possível perceber entre os professores uma visão predominantemente globalizada, ressaltando a relação homem-natureza e entre os alunos prevaleceu uma visão antropocêntrica, evidenciando a natureza como fonte de recursos para a sobrevivência humana. Foi possível perceber que os estudantes e profissionais da educação conhecem os conceitos básicos de ambiente, mas não possuem uma noção clara e objetiva de sua real dimensão. Com essa análise, será possível traçar estratégias e realizar trabalhos de educação ambiental que possam contribuir para que esta comunidade escolar consiga facilmente compreender a complexidade do tema e as possíveis consequências da degradação ambiental e ;sociocultural.

Palavras-chave: Percepção Ambiental, Analfabetismo, Ambiente e Educação Ambiental.

\footnotetext{
${ }^{1}$ Graduado em Ciências Biológicas, IESC/Faculdade Guaraí. Guaraí - TO.

${ }^{2}$ Graduado em Ciências Biológicas, IESC/Faculdade Guaraí. Guaraí - TO.

${ }^{3}$ Bióloga e Biomédica. Especialista em Biologia da Conservação e Docência do Ensino Superior. Mestranda em Ciências Ambientais (Universidade Brasil).

${ }^{4}$ Biólogo, mestre em Ciências Ambientais e Saúde, professor do IESC/Faculdade Guaraí. Guaraí - TO.

${ }^{5}$ Biólogo, mestre em Ciências Ambientais e Saúde, professor do IESC/Faculdade Guaraí. Guaraí - TO.

${ }^{6}$ Biólogo, Especialista em Educação Ambiental, Mestre em Ciências do Ambiente, doutorando em Engenharia Biomédica (Universidade Brasil). Professor do IESC/Faculdade Guaraí, GuaraíTO.
} 


\section{ABSTRACT}

The term environmental illiteracy emerged at the RIO-92 conference after highlighting the need to implement a sustainable model that determines the relationship of people to environmental problems in order to train citizens committed to social and environmental issues. In this context, the research aimed to analyze environmental illiteracy about the perception of teachers and high school students in the municipality of Guaraí-TO, seeking to identify this possible illiteracy. For the development of this work, resources were used to assist in data collection, allowing a clearer view of this possible illiteracy by teachers and students. Through the use of a questionnaire and observations to describe the characteristics of the interviewees, it was possible to perceive among the teachers a predominantly globalized view, emphasizing the relation between man and nature and among the students anthropocentric vision prevailed, evidencing nature as a source of resources for human survival. It was possible to perceive that the students and professionals of the education know the basic concepts of environment, but do not have a clear and objective notion of its real dimension. With this analysis, it will be possible to draw up strategies and carry out environmental education works that can contribute to this school community being able to easily understand the complexity of the theme and the possible consequences of environmental and sociocultural degradation.

Key words: Environmental Perception, Illiteracy, Environment and Environmental Education.

\section{Introdução}

Gradualmente o homem adquiriu uma postura antropocêntrica e que vem se acentuando ao longo do tempo, acreditando que tudo no mundo está para servi-lo (GRÜN, 2009). E quando se fala em degradação ambiental, este mesmo homem é o responsável por tais fatos.

Como consequência da degradação do ambiente, é possível observar em grande parte do mundo uma preocupação com essa problemática. Sabendo que o homem é o responsável por estes problemas ambientais e que tais práticas não afetarão uma única pessoa, essas atitudes poderão ser consideradas como problema da humanidade (CORRALIZA, 1997).

Segundo Padua (2000), com base na Carta de Belgrado (1975), a Educação Ambiental precisa desenvolver no cidadão uma percepção consciente sobre o ambiente como um todo, receoso sobre os problemas relacionados ao ambiente e que possua percepção, atuação, ânimo, motivação, comprometimento e habilidades para colaborar diretamente ou 


\section{AMBIENTE \& EDUCAÇ̃̃̃O \\ ISSN- 1413-8638}

E-ISSN - 2238-5533

v. 23 , n. 1, p. 198-224, 2018

indiretamente buscando solucionar e prevenir os problemas presentes e futuros.

Educar expressa, acima de tudo, a autotransformação, visto que a educação ambiental visa a transformação educacional, política, cultural, formativa, informativa e, sobretudo, emancipatória (LOUREIRO, 2006). Ainda segundo o mesmo autor, é de fundamental importância que esse processo se concretize para formar cidadãos sustentáveis, orientados de modo a encarar os obstáculos contemporâneos a fim de garantir as gerações futuras a qualidade de vida.

É explícito que não será fácil estimular uma mudança na percepção sobre ambiente, já que a mesma provoca alterações nos hábitos econômicos, sociais e culturais. No entanto, um trabalho de educação ambiental poderá ser mais completo se tiver como base uma investigação sobre as formas de percepção do ambiente (MARQUES, 1993).

Jickling (1994), diz que, anteriormente à formulação de quaisquer projetos ou dinâmicas em educação ambiental, é fundamental informar as classificações essenciais. Igualmente, Sauvé (1997), classifica o ambiente em seis concepções paradigmáticas, sendo o ambiente como natureza, recurso, problema, como um lugar, biosfera e como projeto comunitário.

De certo, uma educação ambiental integrada á pratica pedagógica busca promover conhecimentos, procedimentos e valores que conduzam os educandos a mudanças comportamentais, atitudinais e de cidadania, a fim de proporcionar uma nova relação entre homem e ambiente (CAPRÂNICA \& KAWASAKI, 2000).

No entanto, na maioria das escolas se costuma desenvolver trabalhos de forma tradicionais, de ensino simplificado, de grande parte teórica e longe da prática, limitando a compreensão e o envolvimento, consequentemente distanciando o relacionamento do aluno/professor com o ambiente (MENGHINI, 2005).

Segundo Brasil (1996) e United Nations Conference on Environment and Development-UNCED (1992), logo após a Rio-92 é que as políticas de Educação Ambiental tomaram força no Brasil destacando a necessidade da 
Educação Ambiental para o Desenvolvimento Sustentável, surgindo o termo Analfabetismo Ambiental. Este termo surgiu nesta conferência para determinar a relação das pessoas com aos problemas ambientais, com o intuito de implementar um modelo sustentável, a fim de formar cidadãos responsáveis (HELENE \& BICUDO, 1994), preocupados com ambiente e empenhados em garantir as gerações futuras bem-estar e qualidade de vida (EARTH COUNCIL, 1992).

Assim, os prejuízos ambientais são produtos do analfabetismo ambiental atados ao egocentrismo e ambição que se alimenta de um modelo econômico que enxerga o ambiente unicamente como fonte de lucros (LIMA et al, 2010).

Essa pesquisa teve como objetivo analisar o analfabetismo ambiental acerca da percepção dos docentes e discentes do Ensino Médio no município de Guaraí-TO, buscando identificar esse possível analfabetismo através do uso de questionário e observações. E como objetivo específico, nesse contexto, realizar um diagnóstico da percepção de alunos e professores tornando possível uma reflexão e um novo olhar sobre a temática afim nortear as intervenções pra uma EA holística e de qualidade.

Este estudo possui cunho cientifico acadêmico de caráter qualiquantitativo descritivo, de forma a conseguir uma explicação e compreensão mais ampla do tema proposto (GIDDENS, 2012), e descritivo com o intuito de descrever as características de determinadas populações (GIL, 2008).

A pesquisa foi realizada com 85 alunos, matriculados à época do desenvolvimento da pesquisa, 29 de março de 2017, em quatro turmas da $3^{\underline{a}}$ série do ensino médio e com 15 professores, atuantes em diferentes áreas do conhecimento de uma escola pública em Guaraí no Estado do Tocantins.

Para o desenvolvimento desta pesquisa foram utilizados recursos que auxiliassem nos levantamentos de dados a respeito desse possível analfabetismo ambiental, possibilitando uma visão mais clara desse analfabetismo por parte de professores e alunos no município de Guaraí.

A presente pesquisa foi realizada em duas etapas (Etapa 1 e 2):

A Etapa 1, caracterizada por uma pesquisa bibliográfica de modo a ter uma reflexão sobre analfabetismo ambiental, utilizando as seguintes palavras 
chaves "Percepção Ambiental", "Analfabetismo", "Ambiente" e "Educação Ambiental", utilizando artigos na língua portuguesa e estrangeira, publicados em plataformas de periódicos como Sientifc Electronic Library Online (SciELO), Google Acadêmico, Coordenação de Aperfeiçoamento de Pessoal de Nível Superior (CAPES) e livros.

A Etapa 2 se deu através de um questionário (Apêndice II e III) de caráter quali-quantitativo, com uma questão aberta e nove questões fechadas, sendo a primeira parte constituída por questões relacionadas com dados pessoais (idade, sexo, escolaridade, área de formação); e a segunda composta por questões diretamente relacionadas com as percepções sobre ambiente (SLONSKI, 2011).

A análise consistiu na tabulação de informações obtidas em planilhas do Microsoft Excel 2013 para a elaboração de tabelas de maneira rápida e eficaz. As respostas abertas obtidas através do questionário foram transcritas para arquivo de texto do Microsoft Word 2013. E para a obtenção dos resultados foi utilizada a estatística descritiva por porcentagem qualitativa e quantitativa. Segundo Minayo (2007), há duas formas de se realizar uma pesquisa, utilizando dois tipos principais de documentos: a observação e a entrevista. Enquanto que na primeira metodologia de pesquisa é possível observar tudo aquilo que não é mencionado, mas que pode ser observado por um entrevistador atento, na segunda o importante é a escrita do entrevistado que por meio dessa é verificado seus costumes, percepções e sua visão de mundo.

A presente pesquisa contou com a assinatura do termo de consentimento livre e esclarecido (Apêndice l) dos entrevistados após a apresentação da pesquisa aos interlocutores segundo a resolução no 466 de 12 de dezembro de 2012 (BRASIL, 2013).

Conforme relatado na metodologia a análise dos questionários obtidos foram feitos de maneira indutiva e exploratória levando em conta a percepção dos alunos e professores. Dos 100 participantes da pesquisa, 65 são do sexo feminino e 35 do sexo masculino com faixas etárias entre 16 a 60 anos.

Assim, é necessário conhecer a realidade específica da população para que se possa se tomadas atitude em prol da qualidade de vida e bem-estar 
social (RIBEIRO; PERES, 2010). E sendo a escola como um ambiente de práticas educativas e de reflexão sobre a relação do homem com ele mesmo, com seus semelhantes e entre si, torna-se necessário conhecer os empecilhos que levam a uma EA de qualidade (VASCONCELOS, 1997; DIAS, 1992). Justificando assim os interesses desta pesquisa.

\section{Resultados e Discussão}

A primeira pergunta aberta do questionário, pediu aos entrevistados que definissem o ambiente de acordo com seus conceitos predefinidos. Esta questão tinha a intenção de perceber e reconhecer a concepção do ambiente pelos entrevistados. Segundo Reigota (2007), o conceito de ambiente se configura em uma representação social por não haver um consenso de seu significado na comunidade científica. Assim, para Moscovici (1978), representação social é o senso comum que se tem sobre um determinado tema, incluso neste conceito aspectos ideológicos, sociais, profissionais e de conceitos predefinidos pelas pessoas.

Desse modo Reigota (2007) expõe três representações do ambiente: Antropocêntrica, sobressaindo o homem sobre os recursos naturais utilizado para sua sobrevivência; Globalizante, ressaltando a reciprocidade do homem com a natureza; Naturalista, revelando aspectos naturais em sua definição, excluindo o homem do ambiente.

Ao analisar as respostas abertas obtidas nos questionários de professores foi possível a construção da Tabela 1, onde se pode observar um grande percentual da visão globalizante (53\%), fato positivo, pois há a inclusão do homem no ambiente, ressaltando a reciprocidade e que ambos devem viver harmonicamente. Entretanto, também é possível notar entre os professores uma visão antropocêntrica (33\%), de menor predominância, mas de valor não desprezível. 
Tabela 1: Definição do ambiente pelo corpo docente.

\begin{tabular}{|ccc|}
\hline Representações & Professores & $\%$ \\
\hline Antropocêntrica & 5 & $33 \%$ \\
\hline Globalizante & 8 & $53 \%$ \\
\hline Naturalista & 1 & $7 \%$ \\
\hline Não responderam & 1 & $7 \%$ \\
\hline Total & 15 & $100 \%$ \\
\hline
\end{tabular}

Fonte: os autores 2017.

Em relação aos alunos, através da Tabela 2, é possível observar um pequeno grupo de visão naturalista (16\%), como constatam Cunha e Zeni (2007), estes alunos entendem que a sociedade não se relaciona com o ambiente. No entanto, a visão globalizada (33\%) começou a se destacar entre os alunos, explicitando a reciprocidade entre a sociedade e a natureza.

Tabela 2: Definição do ambiente pelo corpo discente.

\begin{tabular}{|ccc|}
\hline Representações & Alunos & $\%$ \\
\hline Antropocêntrica & 40 & $47 \%$ \\
\hline Globalizante & 28 & $33 \%$ \\
\hline Naturalista & 14 & $16 \%$ \\
\hline Não responderam & 3 & $4 \%$ \\
\hline Total & $\mathbf{8 5}$ & $\mathbf{1 0 0} \%$ \\
\hline
\end{tabular}

Fonte: os autores 2017.

Entretanto, é possível observar que grande parte dos alunos possuem uma visão antropocêntrica (47\%), estes resultados se apresentam semelhantes aos encontrados por Rebollar (2009) em alunos do ensino superior na região da grande Florianópolis - SC. Ainda segundo a autora, a predominância dessa visão pode também ter origem nos educadores no repassar das informações ambientais.

As outras 9 perguntas fechadas do questionário foram relacionadas à percepção a respeito dos problemas ambientais a nível local e global, ao grau de envolvimento do entrevistado com ações ambientais e a avaliação a respeito do comprometimento com ações ambientais.

Em seguida Ihes foi questionado quais atividades mais contribuíam para a degradação ambiental, apesar de não haver grandes divergências, entre os alunos os problemas mais citados foram a indústria (29\%), a agricultura (19\%), em seguida a sociedade em geral (13\%), entre os professores a indústria $(25 \%)$, a sociedade em geral (21\%) e a agricultura (19\%) se destacaram. 
Tabela 3: Quais atividades mais contribuem para a degradação ambiental?

\begin{tabular}{|ccc|}
\hline Atividades & Alunos & Professores \\
\hline Agricultura & $19 \%$ & $19 \%$ \\
\hline Comércio & $9 \%$ & $6 \%$ \\
\hline Indústria & $29 \%$ & $25 \%$ \\
\hline Pecuária & $12 \%$ & $17 \%$ \\
\hline Sociedade em geral & $13 \%$ & $21 \%$ \\
\hline Transporte e turismo & $8 \%$ & $8 \%$ \\
\hline Outras atividades & $10 \%$ & $4 \%$ \\
\hline
\end{tabular}

Fonte: os autores 2017.

$\mathrm{Na}$ sequência, Ihes foram pedidos que avaliassem seu envolvimento com ações ambientais, estas, segundo Capra (1996), por mais que se apresentem de forma isolada, são sistêmicas, pois estão interligadas e ao mesmo tempo são independentes. Com as informações obtidas, foi possível a construção da Tabela 4.

Tabela 4: Avaliação do envolvimento em ações ambientais assinalando as alternativas, o que faz ou o que não.

\begin{tabular}{lllll}
\hline \multicolumn{1}{c}{ Ações ambientais } & \multicolumn{2}{c}{ Alunos } & \multicolumn{2}{c}{ Professores } \\
\hline & Sim & Não & Sim & Não \\
\hline Consome produtos orgânicos & $83 \%$ & $17 \%$ & $57 \%$ & $43 \%$ \\
\hline Contribui com entidades ambientais & $41 \%$ & $59 \%$ & $21 \%$ & $79 \%$ \\
\hline Conversa sobre a temática & $41 \%$ & $59 \%$ & $77 \%$ & $23 \%$ \\
\hline $\begin{array}{l}\text { Denuncia agressões/crimes } \\
\text { ambientais }\end{array}$ & $28 \%$ & $72 \%$ & $23 \%$ & $77 \%$ \\
\hline Diminui o uso do automóvel & $45 \%$ & $55 \%$ & $64 \%$ & $36 \%$ \\
\hline Diminui o consumo de água & $73 \%$ & $27 \%$ & $93 \%$ & $7 \%$ \\
\hline Evita produtos descartáveis & $37 \%$ & $63 \%$ & $64 \%$ & $36 \%$ \\
\hline $\begin{array}{l}\text { Participa de projetos ambientais na } \\
\text { comunidade }\end{array}$ & $26 \%$ & $74 \%$ & $36 \%$ & $64 \%$ \\
\hline $\begin{array}{l}\text { Participa de projetos ambientais na } \\
\text { escola }\end{array}$ & $54 \%$ & $46 \%$ & $62 \%$ & $38 \%$ \\
\hline Reduz o consumo de papel & $56 \%$ & $44 \%$ & $79 \%$ & $21 \%$ \\
\hline Reduz o consumo de carne & $25 \%$ & $75 \%$ & $47 \%$ & $53 \%$ \\
\hline
\end{tabular}

Fonte: os autores 2017.

A não redução do consumo de carne por grande parte dos alunos e pouco mais da metade dos professores, reflete nos resultados da Tabela 3, exigindo mais da criação de gado de corte gerando sérios problemas 
ambientais, de acordo com Margulis (2003), a viabilidade financeira da pecuária é o que leva ao desmatamento.

A contribuição com entidades ambientais, conversas sobre a temática e a participação em projetos ambientais na comunidade destacam a falta de envolvimento com ações comunitárias. Entretanto é possível perceber um comprometimento maior no consumo de alimentos orgânicos, participação em projetos ambientais na escola e a redução do consumo de água e papel.

$\mathrm{Na}$ Tabela 2 e 4 é possível observar o comportamento humano de acordo com sua relação e percepção do meio, seguindo sua representação social sobre o ambiente (MENGHINI, 2005). É necessário entender a percepção dos alunos sobre ambiente, uma vez que eles, desde cedo, precisam compreender as leis da vida e como funciona o universo, de modo a entender os problemas relacionados ao ambiente em que estão inseridos para então proteger e cuidar dele (CAPRA, 2000; FAGGIONATO, 2005).

Ao serem questionados em quais meios de comunicação obtinham informações sobre as questões ambientais, a resposta dos professores e alunos apresentaram uma certa semelhança, entre jornal, internet, rádio e outros. No entanto a revista se destaca entre os professores, apresentando uma linguagem mais científica e compreendida por eles, já a televisão prevalece entre os alunos por trazerem uma expressão mais popular e de fácil entendimento.

Tabela 5: Meios de comunicação mais utilizados entre professores e alunos para se informar sobre questões ambientais.

\begin{tabular}{ccc} 
Meios de comunicação & Alunos & Professores \\
\hline Jornal & $18 \%$ & $16 \%$ \\
\hline Internet & $35 \%$ & $31 \%$ \\
\hline TV & $31 \%$ & $24 \%$ \\
\hline Rádio & $4 \%$ & $5 \%$ \\
\hline Revistas & $6 \%$ & $17 \%$ \\
\hline Outros & $6 \%$ & $7 \%$ \\
\hline
\end{tabular}

Fonte: os autores 2017.

Do ponto de vista metodológico, a educação não precisa contrariar a mídia como um todo, porém o estímulo mais crítico torna-se necessário para (re)pensar sobre o que é comunicado, seja o que está escrito ou falado nos diversos meios de comunicação disponíveis, já que não há neutralidade e sim 
um comportamento meramente de caráter ideológico exagerado (FREIRE, 2000).

Colocados frente a uma determinada situação, buscou-se perceber a ação de professores e alunos na solução de um "certo problema", obtendo os seguintes resultados, apresentados na Tabela 6.

Tabela 6: Perto da sua casa tem uma árvore que está cheia de lagartas que "queimam" as crianças, quando brincam junto dela. Você:

\begin{tabular}{|c|c|c|}
\hline Iniciativa & Alunos & Professores \\
\hline $\begin{array}{l}\text { Resolve aplicar um veneno na árvore ou } \\
\text { utilizar outra forma de matá-la. }\end{array}$ & $20 \%$ & $14 \%$ \\
\hline $\begin{array}{l}\text { Afasta as crianças dali no período que as } \\
\text { lagartas estão presentes. }\end{array}$ & $63 \%$ & $73 \%$ \\
\hline $\begin{array}{l}\text { Pede a prefeitura para retirá-la e reconhece } \\
\text { que sem a árvore corre menos riscos. }\end{array}$ & $2 \%$ & $0 \%$ \\
\hline Pede uma indenização à prefeitura. & $2 \%$ & $0 \%$ \\
\hline $\begin{array}{l}\text { Pensa numa forma de substituí-la por outra } \\
\text { espécie. }\end{array}$ & $13 \%$ & $13 \%$ \\
\hline
\end{tabular}

Fonte: os autores 2017.

Com uma atitude ecológica, grande parte dos professores e alunos resolveram afastar as crianças de perto das lagartas, pois sabem que com 0 tempo elas não estarão mais ali. No entanto, $20 \%$ dos alunos e $14 \%$ dos professores, resolveriam o "problema" matando as lagartas com veneno e 13\% dos professores e alunos pensariam em uma forma de substituí-la por uma árvore de outra espécie o que levaria um certo tempo até a nova planta atingir um porte que possibilitaria as crianças de brincarem em sua sombra. Entre os alunos $2 \%$ pediriam a prefeitura para a retirada da árvore, pois acreditam que assim correm menos riscos, estes reduziriam a área verde do seu ambiente sem ao menos pensar em substituí-la por outra espécie.

De acordo com Fraj e Martínez (2003), pessoas mais reflexivas aos problemas ambientais, as atitudes ecológicas tornam-se mais positivas e favoráveis no que tange à ecologia ou ambiente. Do mesmo modo, ainda segundo os autores, a consciência ecológica aliada ao afeto ambiental por parte de alguns indivíduos, teriam uma atitude mais forte, tomando as decisões mais eficazes.

Ao serem indagados a respeito da melhor definição do ambiente, se obteve os seguintes resultados expressos na Tabela 7, a melhor representação 
de ambiente entre alunos (49\%) e professores (80\%) é a que o homem está inserido no ambiente e não um ser isolado.

Tabela 7: Como você acha que seria a melhor definição de meio ambiente

\begin{tabular}{lcc}
\multicolumn{1}{c}{ Definição } & Aluno & Professor \\
$\begin{array}{l}\text { A inter-relação entre a flora, fauna e o } \\
\text { clima. }\end{array}$ & $4 \%$ & $7 \%$ \\
\hline $\begin{array}{l}\text { As paisagens naturais e urbanas. } \\
\begin{array}{l}\text { Tudo o que se relaciona a paisagem } \\
\text { natural: florestas, rios, e seus habitats. }\end{array}\end{array}$ & $5 \%$ & $13 \%$ \\
\hline $\begin{array}{l}\text { O lugar onde o homem e a natureza estão } \\
\text { em constante interação. }\end{array}$ & $49 \%$ & $0 \%$ \\
\hline
\end{tabular}

Fonte: os autores 2017.

"Tudo que se relaciona a paisagem natural" também se destacou entre os alunos como definição do ambiente com $42 \%$, e "As paisagens naturais e urbana" apareceram com 13\% entre os professores. Porém, é importante lembrar que a definição do ambiente é imprecisa por ser uma realidade complexa, escapando de qualquer definição (SAUVÉ \& ORELLANA, 2001).

Segundo Rapoport (1978), ambiente é qualquer influência ou condição externa ao organismo, grupo ou sistema que se estuda. Tuan (1965) define o termo ambiente como as condições que qualquer organismo ou coisa vive ou se modifica sofrendo influência total dos fatores que o desenvolve ou determinam em sua vida ou caráter.

Novamente os professores e alunos foram colocados frente a uma determinada situação, para buscar resolver um problema, desta vez, algo de maior envolvimento com a sociedade. Os dados obtidos tiveram resultados semelhantes entre professores e alunos e foram expressos na Tabela 8.

Tabela 8: Se próximo a sua residência tem um riacho, e esse se encontra cheio de lixo jogado pelas pessoas do bairro, você tomaria as iniciativas de

\begin{tabular}{lcc}
\multicolumn{1}{c}{ Iniciativas } & Aluno & Professor \\
\hline $\begin{array}{l}\text { Conversar com os moradores do bairro a não } \\
\text { jogar lixo no rio }\end{array}$ & $42 \%$ & $53 \%$ \\
\hline $\begin{array}{l}\text { Não se importar com o problema do lixo } \\
\text { jogado no riacho }\end{array}$ & $5 \%$ & $0 \%$ \\
\hline $\begin{array}{l}\text { Entrar em contato com a secretaria de obras } \\
\text { para remover o lixo do rio }\end{array}$ & $45 \%$ & $47 \%$ \\
\hline $\begin{array}{l}\text { Como todo o bairro joga resíduo no rio } \\
\text { também vou jogar }\end{array}$ & $2 \%$ & $0 \%$ \\
\hline \begin{tabular}{l} 
Fonte: os autores 2017. \\
\hline
\end{tabular} & & \\
\hline
\end{tabular}


Entre as iniciativas tomadas por professores e alunos estão a "Conversar com os moradores do bairro a não jogar lixo no rio" e "Entrar em contato com a secretaria de obras para remover o lixo do rio", isso mostra que existe entre professores e alunos uma preocupação em solucionar esta problemática.

Quando perguntados se a temática ambiental já havia sido trabalhada em sala de aula $60 \%$ dos alunos e $97 \%$ dos professores afirmaram que há uma conversa, estes dados podem ser confirmados na Tabela 9. Entretanto, 40\% dos alunos afirmam não haver essa abordagem em sala de aula, porém, o que se observa na Tabela 3 é uma falta de interesse por parte deles em diálogos sobre a temática ambiental. Questionados a justificar suas respostas sobre os temas ambientais trabalhados em sala de aula, foi possível separar as cinco palavras-chaves: Desmatamento, Plantio, Poluição, Preservação e Reciclagem.

Tabela 9: Algum professor já trabalhou a temática ambiental em sala de aula?

\begin{tabular}{ccc}
\hline Alternativa & Alunos & Professores \\
\hline Sim & $60 \%$ & $93 \%$ \\
\hline Não & $40 \%$ & $7 \%$ \\
\hline
\end{tabular}

Fonte: os autores 2017.

Ao serem questionados se a Educação ambiental objetiva preservar somente a natureza, foi possível constatar que professores e alunos possuem uma noção do que é e o do que se trata. No entanto, $21 \%$ dos alunos e $7 \%$ dos professores afirma que o objetivo da EA é a preservação da natureza, estes a confundem com a conservação ambiental.

Silva (2011) ressalta que, embora o preservacionismo e conservacionismo ter surgido nos Estados Unidos, por volta do século XX, são correntes ideológicas diferentes. O primeiro, independentemente do seu valor econômico e utilitário, aborda a proteção da natureza colocando como agente causador do desequilíbrio atual o homem; O segundo, contempla o amor e a feição pela natureza, aliado pelo uso racional dos recursos naturais por meio de uma gestão eficiente (SILVA, 2011; CARVALHO, 2016). 
Tabela 10: A Educação Ambiental é um processo que objetiva o ensino de preservar somente a natureza?

\begin{tabular}{|ccc|}
\hline Alternativa & Alunos & Professores \\
Sim & $21 \%$ & $7 \%$ \\
\hline Não & $79 \%$ & $93 \%$ \\
\hline
\end{tabular}

Fonte: os autores 2017.

Solicitados a justificar sua resposta, os alunos que responderam sim, afirmaram que:

ALUNO 1: "Como o próprio nome diz, educação ambiental. "

ALUNO 2: "Porque o trabalho dele é sobre isso cuidar do meio ambiente e também dos animais."

Conforme as respostas dos alunos que responderam "sim" foi possível perceber que eles entendem a EA como sinônimo de preservação da natureza e é papel dos educadores ambientais preservá-la, se excluindo de qualquer responsabilidade.

Já os alunos que afirmaram que o papel da EA não é somente preservar a natureza, eles disseram que:

ALUNO 3: "Além de nos ensinar a preservar, nos ensina a ter consciência dos problemas que estão acontecendo."

ALUNO 4: "É o processo que ensina promover a conscientização de um modo geral, não só necessariamente a natureza."

Estes alunos conseguem entender que a EA busca sensibilizar 0 indivíduo para as questões ambientais, dando a elas informações e auxiliando na construção de uma consciência crítica, que os possibilitam enfrentar e resolver problemas ambientais e sociais (MOUSINHO, 2003).

Ao serem questionados se a Educação ambiental objetiva preservar somente a natureza, o professor que respondeu "sim" não justificou sua resposta. No entanto, os professores que responderam "não", utilizaram as justificativas a seguir:

PROFESSOR 1: "Nos ensina a conviver com os outros sistemas."

PROFESSOR 2: "Penso que não. Educar o homem para viver em sociedade de maneira saudável e organizada o que terá reflexo no meio ambiente."

PROFESSOR 3: "Trabalhamos a questão do não desperdício, sempre utilizar tudo que preciso." 
Estes professores percebem a EA como uma ação instrutiva duradoura no qual se tem conhecimento sobre a sua globalidade, da relação homemhomem e homem-natureza, dos problemas advindos destas relações e suas profundas causas (CSEAES, 1976).

Segundo os Parâmetros Curriculares Nacionais - PCN's (BRASIL, 2000), a educação ambiental deve ser trabalhada como tema transversal por todas as disciplinas e em todas as séries. Entretanto, as disciplinas e ações que abordam a temática ambiental mais citadas entre os alunos foram a Biologia, Geografia e em projetos escolares como o Dia da Água. Assim é possível perceber, não só nesta escola, que a Educação Ambiental não é trabalhada de forma interdisciplinar, mas somente nestas áreas (CAVALHEIRO, 2008). Essas falhas, advindas da fragmentação do conhecimento em disciplinas torna-se empecilho para o pensamento complexo acerca da implementação da educação ambiental excelente, bem como o uso do ensino tradicional com ênfase em teorias e contextos desatualizados que não reflete a atualidade como um todo nem a realidade local (SATO, 2003; MORIN, 2001a; 2001b).

Todavia, observou-se que para alguns deles, quando se trata de percepções referentes a temática ambiental, a compreensão torna-se fraca (REIGOTA, 2007), caracterizando uma carência e não de fato um analfabetismo com relação as concepções e percepções sobre o tema, considerando a necessidade da melhoria na abordagem sobre a temática, importante essa para o desenvolvimento de uma compreensão clara sobre o ambiente, visando desenvolver um pensamento crítico que auxilie na mudança de compreensão sobre as vertentes que abrangem essa temática (FONSECA, 2007; DIAS, 2001).

É possível perceber que os estudantes e profissionais em educação conhecem os conceitos básicos de ambiente, mas sem nenhuma noção clara e objetiva de sua real dimensão, ambos demonstraram uma visão preeminentemente antropocêntrica, onde o ambiente é visto como sinônimo de recurso, evidenciando o egocentrismo presente entre os homens (REIGOTA, 2007). 


\section{Conclusão}

Através do presente estudo sobre a avaliação do analfabetismo ambiental, nota-se a necessidade de que alunos e professores modifiquem determinadas percepções concretadas e rígidas. Muitos paradigmas e barreiras devem ser quebrados e transformados em ações idealizadoras e construtivas, para que possam ampliando seus horizontes e observar o ambiente como um todo, não apenas como recurso ou se excluindo dele.

É preciso uma melhoria no ensino/aprendizagem no trabalho de discentes e docentes, que permita compreender que a educação ambiental deve ser mais trabalhada nas escolas, principalmente no ensino fundamental, pois quando essas chegarem no ensino médio consigam facilmente compreender a linguagem, a complexidade do tema e as possíveis consequências da degradação ambiental e sociocultural. Sendo fundamental na sua abordagem considerar os aspectos físicos e biológicos e, principalmente, o modo de interação do ser humano com o ambiente como: natureza, recurso, problema, lugar, biosfera e projeto comunitário. Visto que, toda e qualquer ação tomada é recíproca, com consequências a curto, médio e longo prazo.

Portanto, muito ainda precisa ser feito, imprescindivelmente essas percepções e ações deve partir de todos para que se obtenha uma alfabetização ecológica equipada a um desenvolvimento sustentável em prol das novas gerações, só assim alcançaremos cidadãos comprometidos com as questões socioambientais.

\section{Referências bibliográficas}

BRASIL, Secretaria da Educação Fundamental. Parâmetros Curriculares Nacionais: Meio Ambiente e Saúde. V.9. Brasília: MEC/SEF, 2000. . Ministério da Saúde (MS). Conselho Nacional de Saúde. Resolução no 466, de 12 de dezembro de 2012. Diário Oficial da União, DF, 13 jun. 2013. 
Agenda 21. Conferência das Nações Unidas sobre meio ambiente e desenvolvimento. Brasília: Senado Federal, 1996. 585p. (subsecretaria de edições técnicas).

CAPRA, F. Uma nova Compreensão Científica dos Sistemas Vivos. São Paulo: Cultrix, 2000.

A teia da vida: uma nova compreensão científica dos sistemas vivos.Trad.Newton Roberval Eichemberg. São Paulo: Cultrix, 1996. p. 256.

CAPRÂNICA, P.; KAWASAKY, C. S. As concepções ecológicas de estudantes sobre a arborização urbana: subsídio para educação ambiental. In: Anais do VII Encontro Pespectiva de Ensino de Biologia. São Paulo, 2000.

CARVALHO, A. V. Educação Ambiental no Desenvolvimento Sustentável Municipal. DESAFIOS, v. 2, n. 1, p. 97-108, 2016.

CAVALHEIRO, J. S. Consciência ambiental entre professores e alunos da Escola Estadual Básica Dr. Paulo Devanier Lauda. Monografia de Especialização em Educação Ambiental. Universidade Federal de Santa Maria. 2008.

CSEAES - Conferência Sub-Regional De Educação Ambiental Para A Educação Secundária. 1976, Chosica/Peru. Alguns conceitos de educação ambiental. Chosica/Peru, 1976. Disponível em: <http://www.mma.gov.br> . Acesso em: 19 abril 2017.

CORRALIZA, J. A. La Psicología Ambiental y los problemas medioambientales. Papeles del psicólogo. Revista del Colegio Oficial de Psicólogos, Espa nha, v. 67, p. 26-30, 1997.

CUNHA, T.; ZENI, A. L. A representação social de meio ambiente para alunos de ciências e biologia: subsídio para atividades em educação ambiental. Revista Eletrônica do Mestrado em Educação Ambiental (REMEA), Rio Grande, RS, v. 18, p. 151-162, 2007. 
DIAS, G. F. Educação Ambiental: princípios e práticas. São Paulo, Gaia, 1992. MEC/SEF (Secretaria da Educação Fundamental/MEC). Parâmetros curriculares nacionais: temas transversais. Brasília: MEC/SEF, 1998.

A situação da Educação Ambiental no Brasil é fractal. In: MINISTÉRIO DA EDUCAÇÃO (ed.). Panorama da Educação Ambiental no Ensino Fundamental. Brasília: MEC; SEF, 2001.

EARTH COUNCIL. Treaty on environmental education for sustainable societies and global responsability. Brazil: Non Governmental Organization (NGO’s) International, jun., 1992.

FAGIONATTO, S. O que tem haver percepção ambiental com educação ambiental?. São Paulo, mar. 2007. Disponível em: <http://educar.sc.usp.br.> Acesso em: 12 de abril de 2017.

FRAJ, E.; MARTÍNEZ, E. El comportamiento del consumidor ecológico explicado a través de una escala de actitudes. XIV Encuentro de Profesores Universitarios de Marketing. Granada, 2003.

FONSECA, M.J.C.F. A biodiversidade e o desenvolvimento sustentável nas escolas do ensino médio de Belém (PA), Brasil. Educação e Pesquisa, São Paulo, 2007.

FREIRE, P. Pedagogia da indignação: cartas pedagógicas e outros escritos, Ed. UNESP: São Paulo, 2000.

GIDDENS, A. Sociologia. Tradução: Sandra Regina Netz. 6 ed. Porto Alegre: Artmed, 2012.

GIL, A. C. Como elaborar projetos de pesquisa. 4. ed. São Paulo: Atlas, 2008.

GRÜN, M. Ética e educação ambiental: A conexão necessária. $12^{\mathrm{a}}$ ed. Campinas, SP: Papirus, 2009. p 120. 
HELENE, M.; BICUDO, M. Cenário mundial: sociedades sustentáveis. São Paulo: scipione, 1994.

JICKLING, B. Studying sustainable development: problems and possibilities. Canadian Journal of Education, v. 39, n. 3, 1994. p. 231-240.

LIMA, F. C. A. et al. Integração e Aplicação da Educação Ambiental no Projeto Pedagógico Das Escolas Públicas De Ensino Fundamental E Médio Da Cidade De Sao Grabriel-rs. Anais do Salão Internacional de Ensino, Pesquisa e Extensão, v. 2, n. 1, 2010.

LOUREIRO, C. F. B. Complexidade e dialética: contribuições à práxis política e emancipatória em educação ambiental. In: Educação e Sociedade. Vol. 27, n. 94, 2006 p. 131-134.

MARGULIS, S. Causas do desmatamento da Amazônia brasileira. Brasília: Banco Mundial, 2003.

MARQUES, J. G. W. Etnoecologia, educação ambiental e superação da pobreza em áreas de manguezais. In: ENCONTRO NACIONAL DE EDUCAÇÃO AMBIENTAL EM ÁREAS DE MANGUEZAIS, 1, 1993, Maragogipe. Anais I Encontro Nacional De Educação Ambiental em Áreas de Manguezais. Salvador: UFBA, 1993. p. 29-35.

MENGHINI, F. B. As trilhas interpretativas como recurso pedagógico. Dissertação (Mestrado) - Universidade do Vale do Itajaí, 2005.

MINAYO, M. C. S. Trabalho de Campo: Contexto de Observação, Interação e Descoberta. In: MINAYO, M.C.S (Org.). Pesquisa Social: teoria, método e criatividade. Rio de Janeiro: Editora Vozes, 2007.

MORIN, E. Os sete saberes necessários à educação do futuro. 4 ed. São Paulo: Cortez, 2001a.

A cabeça bem-feita: repensar a reforma, reformar 0 pensamento. Rio de Janeiro: Bertrand Brasil, 2001b. 
MOSCOVICI, S.. A representação social da psicanálise. Trad. por Álvaro Cabral. Rio de Janeiro: Zahar, 1978.

MOUSINHO, P. Glossário. In: Trigueiro, A. (Coord.) Meio ambiente no século 21. Rio de Janeiro: Sextante. 2003.

PADUA, S. M. Educação ambiental: um caminho possível para mudanças. In: BRASIL. Ministério da Educação (Org.). Reflexões sobre o panorama da educação ambiental no ensino formal. Brasília: MEC/COEA, 2000.

RAPOPORT, A. Aspectos Humanos de la Forma Urbana: hacia una confrontación de las ciencias sociales con el aiseôo de la forma urbana. Barcelona, Ed. Gustavo Gilli, 1978. 381 p.

REBOLLAR, P. M. Educação Ambiental e os termos meio ambiente e impacto ambiental na visão de alunos do ensino superior da região da grande Florianópolis - SC.Biotemas, Florianópolis, v. 22, n. 2, 2009. p. 173-180.

REIGOTA, M. Meio ambiente e representação social. 7 ed. São Paulo: Cortez, 2007.

RIBEIRO, C. S.; PERES, P. E. C. Atuação Do Serviço Social Na Educação Ambiental Junto Às Famílias Cadastradas No Programa De Agentes Comunitários De Saúde (PACS) em São Sepé, RS. Revista Eletrônica em Gestão, Educação e Tecnologia Ambiental, Santa Maria, v. 1, n. 1, 2010.

SATO, M. Educação ambiental. São Carlos: RIMA, 2003.

SAUVÉ, L. e ORELLANA, I. A. A formação continuada de professores em Educação Ambiental: a proposta do EDAMAZ. In SATO, M. e SANTOS, J. E. (orgs) A contribuição da Educação Ambiental à esperança de Pandora. São Carlos, RIMA. 2001.

SAUVÈ, L. Educação ambiental e desenvolvimento sustentável: uma análise complexa. In: Revista de Educação Pública, Mato Grosso, Universidade Federal do Mato Grosso, c.6, n. 10, p.72-103, 1997. 
SILVA, I. F. Preservação e Conservação da Reserva Legal: novos debates. Universidade Presidente Antônio Carlos-UNIPAC. Faculdade de Ciências Jurídicas e Sociais de Barbacena/FADI, curso de direito. Monografia. 2011. $43 p$.

SLONSKI, G. T. PERCEPÇÃO AMBIENTAL DA COMUNIDADE ESCOLAR DO INSTITUTO FEDERAL-SC CAMPUS FLORIANÓPOLIS-CONTINENTE. VI Encontro Pesquisa em Educação Ambiental. Ribeirão Preto, 2011.

TUAN, Y. Environment and world. The Professional Geographer, v. 17, n. 5, 1965. p. 6-8.

UNCED. Agenda 21 - program of actions for sustainable development: Rio declaration on environmental and development. New York: United Nations, 1992. (United Nations Conference on Environmental and Development UNCED -, June 1992, Rio de Janeiro, Brazil).

VASCONCELLOS, H. S. R. A pesquisa-ação em projetos de Educação Ambiental. In: PEDRINI, A. G. (org). Educação Ambiental: reflexões e práticas contemporâneas. Petrópolis, Vozes, 1997. 
Apêndice I

\section{TERMO DE CONSENTIMENTO LIVRE E ESCLARECIDO}

Nome da Pesquisa: Analfabetismo Ambiental: A Percepcão dos Docentes e Discentes sobre o Ambiente.

O presente questionário busca identificar o analfabetismo ambiental acerca da percepção dos docentes e discentes do ensino médio no município de GUARAÍ-TO.

A coleta será realizada por meio de um questionário e entrevistas com nove perguntas fechadas e uma aberta, registradas pelos pesquisadores, após o entrevistado estar ciente deste documento.

Sua participação é de grande importância para o sucesso desta pesquisa.

Tendo recebido as informações contidas neste documento e após esclarecimento dos direitos relacionados a seguir, declaro estar ciente do exposto e desejo participar da pesquisa.

$\checkmark$ A garantia de receber a resposta a qualquer pergunta ou esclarecimento a dúvidas sobre os procedimentos, riscos, benefícios e outros relacionados com a pesquisa.

$\checkmark$ A liberdade de retirar meu consentimento a qualquer momento e deixar de participar do estudo.

$\checkmark$ A segurança de que não serei identificado e que será mantido o caráter confidencial das informações relacionadas com a minha privacidade.

$\checkmark$ Compromisso de me proporcionar informações atualizadas durante o estudo, ainda que possa afetar minha vontade de continuar participando.

TERMO DE CONSENTIMENTO

Nome:

/2017.

$R G$ :

Assinatura:

Acadêmicos: Karla Caroline Sousa Dornelas e Natanael Gomes Lima.

Professor Orientador: Aluísio Vasconcelos de Carvalho. 
Apêndice II

Área de formação:

\section{QUESTIONÁRIO PARA PROFESSORES}

Formação: ( ) Graduado ( ) Especialista ( ) Mestre ( ) Doutor

Idade: anos.

Sexo: ( ) Feminino ( ) Masculino

Tempo de atuação na Educação:

1. Com base em sua compreensão do assunto, diga o que é ambiente?

2. Quais atividades humanas mais contribuem para a degradação ambiental?

\begin{tabular}{|l|l|}
\hline & Agricultura \\
\hline & Comércio \\
\hline & Indústria \\
\hline & Pecuária \\
\hline & $\begin{array}{l}\text { Sociedade } \\
\text { geral }\end{array}$ \\
\hline & Transporte turismo \\
\hline & Outras atividades \\
\hline
\end{tabular}

3. Avalie seu envolvimento em ações ambientais assinalando em todas as alternativas, o que faz regularmente ou o que não faz.

\begin{tabular}{|l|l|r|}
\hline Consome produtos orgânicos & ( ) Faço regularmente & ( ) Não faço \\
\hline $\begin{array}{l}\text { Contribui com entidades } \\
\text { ambientais }\end{array}$ & ( ) Faço regularmente & ( ) Não faço \\
\hline Conversa sobre a temática & ( ) Faço regularmente & ( ) Não faço \\
\hline $\begin{array}{l}\text { Denuncia agressões/crimes } \\
\text { ambientais }\end{array}$ & ( ) Faço regularmente & ( ) Não faço \\
\hline Diminui o uso do automóvel & ( ) Faço regularmente & ( ) Não faço \\
\hline Diminui o consumo de água & ( ) Faço regularmente & ( ) Não faço \\
\hline Evita produtos descartáveis & ( ) Faço regularmente & ( ) Não faço \\
\hline $\begin{array}{l}\text { Participa de projetos ambientais } \\
\text { na comunidade }\end{array}$ & ( ) Faço regularmente & ( ) Não faço \\
\hline $\begin{array}{l}\text { Participa de projetos ambientais } \\
\text { na escola }\end{array}$ & ( ) Faço regularmente & ( ) Não faço \\
\hline Reduz o consumo de papel & ( ) Faço regularmente & ( ) Não faço \\
\hline Reduz o consumo de carne & ( ) Faço regularmente & ( ) Não faço \\
\hline
\end{tabular}

4. Quais os meios de comunicação utilizados por você para se informar sobre as questões ambientais? 
AMBIENTE \& EDUCAÇÃo

ISSN- 1413-8638

E-ISSN - 2238-5533

v. 23, n. 1, p. 198-224, 2018

\begin{tabular}{|l|l|}
\hline & Jornal \\
\hline & Internet \\
\hline & TV \\
\hline & Revistas \\
\hline & Rádio \\
\hline & Outros \\
\hline
\end{tabular}

5. A Educação Ambiental é um processo que objetiva o ensino de preservar somente

natureza?

\begin{tabular}{|l|l|l|}
\hline Sim & & Não \\
\hline
\end{tabular}

Justifique:

6. Assinale, entre os problemas abaixo, o que você acha que tem relação com a temática ambiental.

\begin{tabular}{|l|l|l|l|}
\hline & Natureza & & Recurso \\
\hline & Lugar & & Problema \\
\hline & Biosfera & & Projeto comunitário \\
\hline
\end{tabular}

7. Perto da sua casa tem uma árvore que está cheia de lagartas que "queimam" as crianças, quando brincam junto dela. Você resolve:

\begin{tabular}{|l|l|}
\hline & Aplicar um veneno na árvore ou utilizar outra forma de matá-la. \\
\hline & Afasta as crianças dali no período que as lagartas estão presentes. \\
\hline $\begin{array}{l}\text { Pede a prefeitura para retirá-la e reconhece que sem a árvore corre } \\
\text { menos riscos. }\end{array}$ \\
\hline & Pede uma indenização a prefeitura. \\
\hline & Pensa numa forma de substituí-la por outra espécie. \\
\hline
\end{tabular}

Outras soluções:

8. Como você acha que seria a melhor definição de meio ambiente:

\begin{tabular}{|l|l|}
\hline & A inter-relação entre a flora, fauna e o clima. \\
\hline & As paisagens naturais e urbanas. \\
\hline $\begin{array}{l}\text { Tudo o que se relaciona a paisagem natural: florestas, rios, e seus } \\
\text { habitats. }\end{array}$ \\
\hline O lugar onde o homem e a natureza estão em constante interação. \\
\hline
\end{tabular}


9. Algum professor já trabalhou a temática ambiental em sala de aula?

\begin{tabular}{|l|l|l|}
\hline & Sim & Não \\
\hline
\end{tabular}

Quais?

10. Se próximo a sua residência tem um riacho, e esse se encontra cheio de lixo jogado pelas pessoas do bairro, você tomaria as iniciativas de:

\begin{tabular}{|l|l|}
\hline & Conversar com os moradores do bairro a não jogar lixo no rio. \\
\hline & Não se importar com o problema do lixo jogado no riacho. \\
\hline $\begin{array}{l}\text { Entrar em contato com a secretaria de obras para remover o lixo do } \\
\text { rio. }\end{array}$ \\
\hline Como todo o bairro joga resíduo no rio também vou jogar. \\
\hline
\end{tabular}


Apêndice III

\section{QUESTIONÁRIO PARA ALUNOS}

Idade: anos.

Sexo: ( ) Feminino ( ) Masculino

1. Com base em sua compreensão do assunto, diga o que é ambiente?

2. Quais atividades humanas mais contribuem para a degradação ambiental?

\begin{tabular}{|l|l|}
\hline & Agricultura \\
\hline & Comércio \\
\hline & Indústria \\
\hline & Pecuária \\
\hline & $\begin{array}{l}\text { Sociedade } \\
\text { geral }\end{array}$ \\
\hline & Transporte turismo \\
\hline & Outras atividades \\
\hline
\end{tabular}

3. Avalie seu envolvimento em ações ambientais assinalando em todas as alternativas, o que faz regularmente ou o que não faz.

\begin{tabular}{|l|l|r|}
\hline Consome produtos orgânicos & ( ) Faço regularmente & ( ) Não faço \\
\hline $\begin{array}{l}\text { Contribui com ( ) Não faço } \\
\text { ambientais }\end{array}$ & ( ) Faço regularmente & ( ) Não faço \\
\hline Conversa sobre a temática & ( ) Faço regularmente & ( ) Não faço \\
\hline $\begin{array}{l}\text { Denuncia agressões/crimes } \\
\text { ambientais }\end{array}$ & ( ) Faço regularmente & ( ) Não faço \\
\hline Diminui o uso do automóvel & ( ) Faço regularmente & ( ) Não faço \\
\hline Diminui o consumo de água & ( ) Faço regularmente & ( ) Não faço \\
\hline Evita produtos descartáveis & ( ) Faço regularmente & ( ) Não faço \\
\hline $\begin{array}{l}\text { Participa de projetos ambientais } \\
\text { na comunidade }\end{array}$ & ( ) Faço regularmente & ( ) Não faço \\
\hline $\begin{array}{l}\text { Participa de projetos ambientais } \\
\text { na escola }\end{array}$ & ( ) Faço regularmente & ( ) Não faço \\
\hline Reduz o consumo de papel & ( ) Faço regularmente & ( ) Não faço \\
\hline Reduz o consumo de carne & ( ) Faço regularmente &
\end{tabular}

4. Quais os meios de comunicação utilizados por você para se informar sobre as questões ambientais?

\begin{tabular}{|l|l|}
\hline & Jornal \\
\hline
\end{tabular}




\begin{tabular}{|l|l|}
\hline & Internet \\
\hline & TV \\
\hline & Rádio \\
\hline & Revistas \\
\hline & Outros \\
\hline
\end{tabular}

5. A Educação Ambiental é um processo que objetiva o ensino de preservar somente natureza?

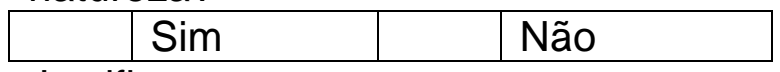

Justifique:

6. Assinale, entre os problemas abaixo, o que você acha que tem relação com a temática ambiental.

\begin{tabular}{|l|l|l|l|}
\hline & Natureza & & Recurso \\
\hline & Lugar & & Problema \\
\hline & Biosfera & & Projeto comunitário \\
\hline
\end{tabular}

7. Perto da sua casa tem uma árvore que está cheia de lagartas que "queimam"

as crianças, quando brincam junto dela. Você:

\begin{tabular}{|l|l|}
\hline & Resolve aplicar um veneno na árvore ou utilizar outra forma de matá-la. \\
\hline & Afasta as crianças dali no período que as lagartas estão presentes. \\
\hline $\begin{array}{l}\text { Pede a prefeitura para retirá-la e reconhece que sem a árvore corre } \\
\text { menos riscos. }\end{array}$ \\
\hline & Pede uma indenização a prefeitura. \\
\hline & Pensa numa forma de substituí-la por outra espécie. \\
\hline
\end{tabular}

8. Como você acha que seria a melhor definição de meio ambiente:

\begin{tabular}{|l|l|}
\hline & A inter-relação entre a flora, fauna e o clima. \\
\hline & As paisagens naturais e urbanas. \\
\hline & $\begin{array}{l}\text { Tudo o que se relaciona a paisagem natural: florestas, rios, e seus } \\
\text { habitats. }\end{array}$ \\
\hline & O lugar onde o homem e a natureza estão em constante interação. \\
\hline
\end{tabular}


9. Algum professor já trabalhou a temática ambiental em sala de aula?

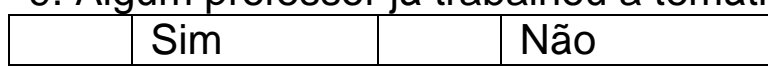

Quais?

10. Se próximo a sua residência tem um riacho, e esse se encontra cheio de lixo

jogado pelas pessoas do bairro, você tomaria as iniciativas de:

\begin{tabular}{|l|l|}
\hline & Conversar com os moradores do bairro a não jogar lixo no rio. \\
\hline & Não se importar com o problema do lixo jogado no riacho. \\
\hline $\begin{array}{l}\text { Entrar em contato com a secretaria de obras para remover o lixo do } \\
\text { rio. }\end{array}$ \\
\hline Como todo o bairro joga resíduo no rio também vou jogar. \\
\hline
\end{tabular}

